\title{
CORPUS RESEARCH ON HEDGES IN APPLED LNGUISTICS AND EFL JOURNAL PAPERS
}

\author{
Shih-Ping Wang \\ Khunkhenova Tatiana \\ National Taiwan University of S \& T \\ spwang2005@yahoo.com.tw
}

First draft received: 30 April 2016

Final proof received: 24 August 2016

\begin{tabular}{l} 
Abstract \\
There has been a considerable increase in the number of studies on hedges that can help authors to \\
reduce commitment and negotiate the meaning between the reader and the writer. This study examines \\
hedging devices based on corpus-based analysis of 750 research articles $(4,831,500$ running words) \\
extracted from 15 leading journals in the areas of linguistics and EFL. Wordsmith Tools 5.0 was used for \\
identifying hedging devices. The frameworks of both Hyland (1998a, 2005) and Varttala (1998) were \\
integrated to identify the functions of hedging devices. The results reveal that modal auxiliary hedging \\
(44.9\%) is found more than the other types, while the noun category is the least used (2.17\%). \\
However, the use of different syntactic features (personal or impersonal) when combined with epistemic \\
lexical terms appeared to influence different interpretations of lexical hedging mainly regarding the \\
politeness strategy. Additionally, it is the authors' responsibility to hedge their own propositions. \\
Learners should know the rules of hedges to distinguish real facts and findings from researchers' biased \\
views and conclusions, and to use these markers accurately in their own works. The current study is \\
practical for EFL learners as it discusses many types of hedges for familiarizing students with the \\
appropriate use of hedging. \\
Keywords: Corpus, hedges, EFL, journal articles \\
To cite this paper (in APA style): \\
Wang, S. (2016). Corpus research on hedges in applied linguistics and EFL journal papers. International \\
Journal of Education, $9(1), 44-51$. doi: dx.doi.org/10.17509/ije.v9i1.3717 \\
\hline \hline
\end{tabular}

\section{INTRODUCTION}

Hedges are critical in academic writing (Hyland, 2005; Wishnoff, 2000). They are a rhetorical device, indicating the writer's decision to withhold complete commitment to a proposition, allowing for the expression of the writer's opinion rather than fact.

First, a writer needs to present his/her claim with some degree of certainty. Dahl (2008) reported that scholars in the fields of linguistics and economics present their new claims in the Introduction section of their research articles (RA) with a high degree of assertiveness as a rhetorical strategy to win the publishing competition. In short, hedges represent a major contribution to the social negotiation of knowledge and writers' efforts to persuade readers and to gain community acceptance for their work (Hyland, 2000). Studies designed to examine the use of hedges in RAs have largely examined English texts from different disciplinary fields (Dahl, 2008; Silver, 2003).

The studies of hedges in research articles demonstrate the pervasiveness of both rhetorical devices not only in disciplines relying on verbal argumentation, but also in those fields which deal with the so-called objective, measurable data, and hard knowledge domain, such as physics (e.g., Hyland, 2005). This suggests that hedges play a dual role: to constitute central pragmatic features in the process of engaging, and to persuade readers to accept the writer's claims (Hyland, 2005; Lewin, 2005).

\section{LITERATURE REVIEW}

Linguistic Hedging

Hedging is a genre-specific subject matter (Vass, 2004). Fraser (2010) offered some examples of English hedges and their associated linguistic analysis, for example:

Modal adverbs (perhaps, possibly, probably, practically, presumably, apparently):

e.g., I can possibly do that.

Modal adjectives (possible, probable, un/likely)

e.g., It is possible that...

Modal nouns (assumption, claim, possibility, estimate, suggestion)

e.g., The assumption here is that...

Modal verbs (might, can, would, could)

e.g., John might leave now

Fraser (2010) also presents the notion that the focus of hedging may range from a single word to a speech act. For example:

a) Word - He's basically a [bachelor].

b) Phrase - He has a somewhat [elevated temperature].

c) Proposition - As far as I can tell, [you won't have problems].

d) Speech Act - I must [request] that you sit down. 


\section{Framework for identifying hedging devices}

Hyland (1998a) analyzed hedging in writing, involving the following levels of linguistic description and inquiry: (1) Quantitative surface-level analysis of hedges employed in the particular genre; and (2) Pragmatic analysis of their functions.

Varttala (1998) proposed a framework for identifying hedging devices based on the selection and examination of typical epistemic lexical items. This framework includes five central word classes, namely modal auxiliaries (e.g., may), main verbs (argue, believe), adverbs (possibly, perhaps), adjectives (potential, probable) and nouns (hypothesis, idea, notion), as shown in Figure 1.

This study integrated both Varttala's (1998) and Hyland's (1998a) frameworks into the modified framework for identifying hedging devices in the first step of Hyland's quantitative surface-level analysis employed in the genre of EFL.

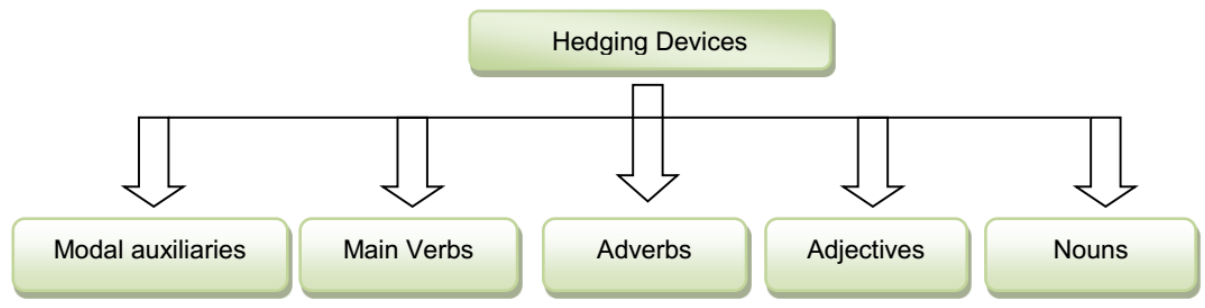

Figure 1. Theoretical Framework for Identifying Hedging Devices (adapted from Varttala, 1998, p. 183)

\section{Aim and research questions}

Hyland (2005) argues that a hedge by its very nature represents a form of mitigation between writers and readers. This study aims to explore (1) different grammatical forms, (2) types of hedging devices and (3) their functions in applied linguistics and EFL journal articles. The following research questions guide the present study:

1. What are the major grammatical forms of hedging devices employed in EFL education research articles?

2. What are the frequencies of the identified hedging devices in the compiled corpus?

3. What are the functions of the identified hedging devices in EFL education research articles?

\section{METHOD}

\section{Data collection}

Table 1 provides detailed information about the journals and the number of articles selected from each journal to construct the corpus for the current study.

Table 1. The number of articles for data analysis and size of sub-corpora (750 papers)

\begin{tabular}{|c|c|c|c|}
\hline $\mathbf{N}$ & Journals & Tokens & $\begin{array}{l}\text { Impact } \\
\text { factor } \\
\text { (SSCl) }\end{array}$ \\
\hline 1 & System & 282,200 & 0.721 \\
\hline 2 & TESOL Quarterly & 392,300 & 0.94 \\
\hline 3 & $\begin{array}{l}\text { Teaching and Teacher } \\
\text { Education }\end{array}$ & 458,200 & 1.413 \\
\hline 4 & Lingua & 491,400 & 0.647 \\
\hline 5 & Journal of Pragmatics & 331,800 & 0.831 \\
\hline 6 & $\begin{array}{l}\text { Linguistics } \\
\text { Education }\end{array}$ & 262,850 & $\begin{array}{l}\text { NA } \\
\text { (Elsevier) }\end{array}$ \\
\hline 7 & $\begin{array}{l}\text { Journal of Second } \\
\text { Language Writing }\end{array}$ & 291,650 & 1.773 \\
\hline 8 & $\begin{array}{l}\text { English for Specific } \\
\text { Purposes }\end{array}$ & 405,900 & 1.659 \\
\hline 9 & $\begin{array}{l}\text { Journal of English for } \\
\text { Academic Purposes }\end{array}$ & 262,400 & 1.019 \\
\hline 10 & Applied Linguistics & 398,850 & 1.45 \\
\hline 11 & ELT Journal & 296,100 & 0.720 \\
\hline 12 & Language Awareness & 221,400 & 0.548 \\
\hline 13 & Assessing Writing & 304,300 & $\begin{array}{l}\text { NA } \\
\text { (Elsevier) }\end{array}$ \\
\hline
\end{tabular}

\begin{tabular}{llll}
\hline $\mathbf{N}$ & Journals & Tokens & $\begin{array}{l}\text { Impact } \\
\text { factor } \\
\text { (SSCl) }\end{array}$ \\
\hline 14 & $E L T$ & 193,580 & NA \\
\hline 15 & $\begin{array}{l}\text { Language Learning } \\
\text { Journal }\end{array}$ & 238,570 & 1.161 \\
\hline $\begin{array}{l}\text { Total (50 papers for } \\
\text { each journal x 15 }=\end{array}$ & & \\
\hline 750$)$ & & \\
\hline
\end{tabular}

The research data for the present study comprised 750 research articles from 15 leading journals (12 $\mathrm{SSCl}$ journals) published from 2008 to 2014. Once the articles were collected, they were converted from pdf- to txt-format (plain text), and were then further combined into one text file as the research corpus for the present study.

For example, Table 2 shows the Top 10 content words in the corpus, revealing that the compiled corpus is relevant to language learning and English teaching research.

Table 2. Top 10 content words within the list top 100 words in the corpus

\begin{tabular}{clcc}
\hline Ranking & Word & Frequency & $\%$ \\
\hline 1 & Language & 48492 & 0.97 \\
\hline 2 & Learning & 34662 & 0.69 \\
\hline 3 & English & 34221 & 0.68 \\
\hline 4 & Students & 32526 & 0.65 \\
\hline 5 & Teaching & 16827 & 0.33 \\
\hline 6 & Teachers & 16786 & 0.33 \\
\hline 7 & Study & 13868 & 0.27 \\
\hline 8 & Teacher & 12636 & 0.25 \\
\hline 9 & Research & 11720 & 0.23 \\
\hline 10 & Learners & 11413 & 0.22 \\
\hline
\end{tabular}

Data analysis, analytical tools, and procedure

The main objective of the present study was twofold: to identify and classify linguistic devices which act as hedges in the discipline of applied linguistics with a special emphasis on EFL/ESL teaching and learning. The second objective is to analyze the functions of identified hedges in the theoretical framework, in other words, the integration of Hyland's (1998a) and Varttala's (1998) frameworks. The procedure of data analysis included the following steps:

First of all, the corpus was analyzed using Wordsmith Tools 5.0. A list of common hedging 
devices was compiled based on Varttala's classification of hedges and Hyland's examples. Then, due to the highly contextual nature of hedges, the electronic search was followed by a manual examination of the identified items. All identified items were scrutinized in their context to select only those linguistic items that expressed uncertainty, probability or mitigation.

Thirdly, a quantitative analysis was conducted to determine the frequency of different hedging means across the genre of EFL teaching and learning. The number of words in each corpus differed, but the corpora were normalized by examining the frequency of hedges in terms of their occurrence per 1,000 words in each corpus.

The procedure for calculating the relative frequency per 1,000 words is as follows (Evison, 2010): The raw number of the particular item was initially determined, and was then multiplied by 1,000 . The result was divided by the total number of words in the specified section. In addition to the relative frequency per 1,000 words, the relative percentage of a particular hedging device was also calculated.

Finally, all hedging forms were analyzed in terms of functions in the chosen genre. The qualitative analysis was based on Hyland's (1998a) poly-pragmatic model of hedging function. Varttala (1998) noted that hedges are best described as "polypragmatic," as expressions whose meaning can rarely be interpreted in one way only.

\section{Theoretical model for analyzing hedging functions}

Hyland (1998a) suggested that the taxonomy be used to identify the function of hedge words in a corpus as shown in Figure 2.

This taxonomy is organized and easy to detect It is also more concise and practical than other taxonomies. Hyland (1998a) proposed the following generalizations:

- Where the principal role of the hedging device is to specify the extent to which a term accurately describes the reported phenomena, it is likely to be acting as an attribute hedge.

- Where the principal role of the hedging device is to convey the writer's assessment of the certainty of the truth of a proposition, then it is likely to be performing a reliability function.

- Where the device occurs in a context which conceals the writer's viewpoint and avoids personal responsibility for propositional truth, then it is probably acting as a writer-oriented hedge.

- Where the writer acknowledges personal responsibility for the validity of propositional content or invites reader involvement, then the device is likely to be acting as a reader-oriented hedge.

Both Figure 1 (for identifying hedging devices) and Figure 2 (for hedges in discourse) were integrated for data analysis in the current study.

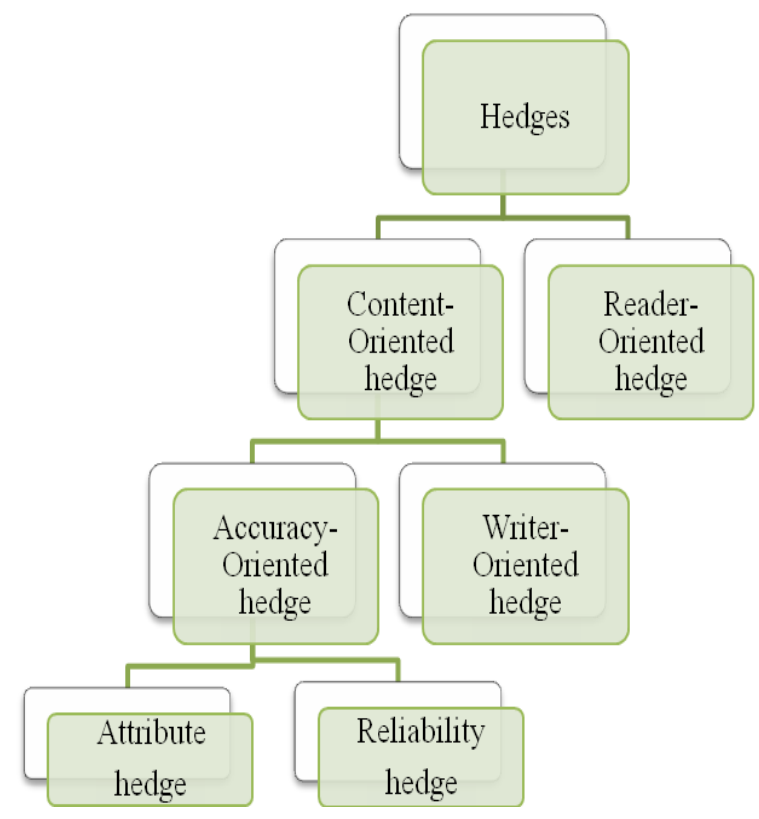

Figure 2. Hyland's Model of Hedges in Scientific Discourse (1998a, p.156)

\section{RESULTS}

RQ1: What are the major grammatical forms of hedging devices employed in EFL academic research articles?

Table 3 presents the overall distribution of hedging forms by category in the corpus of EFL teaching and learning research articles. The results also presented the number of occurrences per thousand words in the second column, while the third column shows the relative percentage of each category. Put simply, F1 means the raw frequency, and F2 means frequency per 1,000 words. The primary categories of hedges in the corpus are modal auxiliary verbs (44.9\%), followed by adverbs (33.45\%), adjectives (10.2\%), main verbs $(9.26 \%)$, and the least frequent category of hedging devices appears to be nouns $(2.17 \%)$.

The frequency of hedging devices per thousand words in the compiled corpus is 14.35 , which means 
that $1.44 \%$ of words in the whole corpus are hedges. This finding indicates that the total number of such devices in EFL education research articles is relatively low.

Table 4 demonstrates that there are only four functional words in the corpus that can potentially act as hedges among the top hundred words in the corpus. As can be seen, modal auxiliary verbs (can, may) appear to be the most prominent category of hedging devices along with approximators (about, some).

Table 3. Distribution of hedging categories across the compiled corpus

\begin{tabular}{lccc}
\hline Categories & F1 & F2 & \% \\
\hline Modal auxiliaries & 30,916 & 6.45 & 44.9 \\
\hline Adverbs & 23,031 & 4.80 & 33.45 \\
\hline Adjectives & 7,025 & 1.46 & 10.2 \\
\hline Main verbs & 6,380 & 1.33 & 9.26 \\
\hline Nouns & 1,499 & 0.31 & 2.17 \\
\hline Total & 68,851 & $\begin{array}{c}14.35 \\
(=1.44 \%)\end{array}$ & 100 \\
\hline
\end{tabular}

Table 4. Rank and frequency of hedging devices in the list of top 100 words

\begin{tabular}{cccc}
\hline Rank & Word & Frequency & $\%$ \\
\hline 42 & Can & 10,725 & 0.21 \\
\hline 53 & About & 8,309 & 0.16 \\
\hline 78 & May & 5,779 & 0.11 \\
\hline 79 & Some & 5,748 & 0.11 \\
\hline
\end{tabular}

RQ2: What are the frequencies of identified hedging devices in the compiled corpus?

According to Varttala (1998), typical epistemic lexical items represent five central word-classes, namely modal auxiliaries, main verbs, adverbs, adjectives and nouns. The following paragraphs examine the frequency of lexical items in the compiled corpus of EFL education research articles.

\section{Modal auxiliary verbs acting as hedges}

It is well known that modal auxiliaries cover a wide range of meanings. Modality is traditionally divided into two major categories: root and epistemic. Hedging concerns the latter, since both epistemic modality and hedging express the degree of the speaker's or writer's confidence in the proposition (Falahati, 2007). Table 5 shows the comparative percentage of different modal auxiliaries in the corpus of the present study.

Table 5. Frequencies of modal auxiliary verbs used as hedges in the corpus

\begin{tabular}{lccc}
\hline Modal auxiliary verbs & F1 & F2 & $\%$ \\
\hline can & 10,726 & 2.24 & 34.7 \\
\hline may & 5,779 & 1.21 & 18.7 \\
\hline should/wouldn't & 4,710 & 0.98 & 15.2 \\
\hline could/couldn't & 4,003 & 0.83 & 12.9 \\
\hline might & 3,443 & 0.71 & 11.1 \\
\hline Total & 2,255 & 0.47 & 7.3 \\
\hline
\end{tabular}

The most frequent modal auxiliary verb in the corpus is can. It accounts for $34.7 \%$ out of the total of 30,916 , which is almost twice as frequent as the second frequent modal auxiliary verb may.

The result suggests that EFL education researchers are more concerned about the ability of students to perform language skills before and after different research experiments or this modal auxiliary verb is used just to describe the student's performance if the studies do not imply manipulations. After can, the most commonly used auxiliary verb in the compiled corpus is may. The remaining forms (would/wouldn't, should/shouldn't, could/couldn't, might) account the rest $50 \%$ of the total. The following are examples of modal auxiliaries acting as hedging devices in the EFL education research articles. In (1), we can observe the double use of the modal verb can, and in both cases it fulfills the function of hedging. The second sentence (2) expresses the possibility of the proposed statement. The author supports his/her mitigation by referring to the other source.

(1) Such information can provide insights into how AFL can be integrated into the writing classroom.

(2) Since the self-image of ELT-professionals may be context dependent (Samimy and BruttGriffler, 1999), it is important to conduct studies also in EFL settings.

In (3), (4) and (5), the authors try to fit in the conventional academic writing style while proposing the idea by using the modal auxiliary would, could, and might, which indicates the author's wish to remain humble (politeness strategy). In short, the category of modal auxiliary hedges was found as one of the most prominent categories in the genre of EFL education research articles.

(3) Second, it would be valuable to attempt to generalize these findings to additional phonetic context.

(4) The children in our study could be described, after intervention, as being at the orthographic stage, because they demonstrated strategies beyond the alphabetic stage.

(5) For these students, school might be the only setting where they have the opportunity to encounter and acquire academic language, and their teachers might be the most significant single source of oral academic discourse.

\section{Main verbs acting as hedges}

Varttala (2001) considered lexical verbs as an even more exponent of modality than the modal auxiliaries. Hyland (1998a, p. 119) argued that epistemic verbs are "the most transparent means of coding the subjectivity of the epistemic source," and they are generally used to hedge either commitment or assertiveness. Additionally, epistemic lexical verbs are considered the most frequent means of expressing mitigation. Table 6 shows the percentage of different epistemic verbs acting as hedging identified in the corpus of the present study.

Table 6. Frequencies of the Top 10 verbs used as hedges

\begin{tabular}{clccc}
\hline $\mathbf{N}$ & Main verbs & $\mathbf{F 1}$ & $\mathbf{F 2}$ & $\%$ \\
\hline 1 & Suggest & 1024 & 0.21 & 16.05 \\
\hline 2 & Indicate & 910 & 0.19 & 14.3 \\
\hline 3 & Seem & 638 & 0.13 & 10.0 \\
\hline 4 & Believed & 593 & 0.12 & 9.3 \\
\hline 5 & Appear & 503 & 0.10 & 7.9 \\
\hline 6 & Tend & 480 & 0.10 & 7.5 \\
\hline 7 & Argue & 399 & 0.08 & 6.25 \\
\hline 8 & seen as & 377 & 0.08 & 5.9 \\
\hline 9 & Perceive & 275 & 0.06 & 4.3 \\
\hline 10 & Predict & 59 & .05 & .05 \\
\hline
\end{tabular}


The verbs provide writers with a number of ways to signify the non-factual status of a proposition. The most frequent epistemic verbs across the compiled corpus are suggest (16.05\%), indicate (14.3\%) and seem $(10 \%)$. These findings appear to be logical as we deal with the genre of education research. Therefore, researchers suggest what their findings indicate on and try to make humble conclusions by the word seem. The following sentences are examples of verbs as hedges in the corpus:

(6) At the same time, this may suggest that it is not the mastery or avoidance of specific grammatical structures that it is important per se, but rather the ability to control meaning.

(8) Moreover, this differential impairment might indicate a differential representation of these languages.

(9) Perhaps due to contemporary economic pressures, interventionist education and language policies seem to have become a permanent part of teacher's work.

(10) While the potential role of computer technology in language learning and teaching is enormous, hence, to know more about the role of CALL in EFL settings, it is believed that taking into account students' views and competence in CALL will shed more light on the field.

(11) As described above, these features also appear to be true of language teacher cognition.

\section{Adverbs acting as hedges}

In addition to modal auxiliaries, there are other ways of expressing epistemic modality. In this sense, hedging is also frequently expressed by epistemic adverbs, which can introduce a certain degree of indefiniteness or lack of precision to the information. Table 7 shows the comparative percentage of different adverbs acting as hedges identified in the corpus of the present study.

Table 7. Frequencies of adverbs potentially used as hedges in the corpus

\begin{tabular}{clccc}
\hline $\mathbf{N}$ & Adverbs & F1 & F2 & $\%$ \\
\hline 1 & About & 8309 & 1.73 & 36.08 \\
\hline 2 & Often & 2118 & 0.44 & 9.20 \\
\hline 3 & Rather & 2072 & 0.43 & 9.00 \\
\hline 4 & Likely & 1071 & 0.22 & 4.65 \\
\hline 5 & generally & 793 & 0.17 & 3.44 \\
\hline 6 & (not)always & 791 & 0.16 & 3.43 \\
\hline 7 & frequently & 741 & 0.15 & 3.22 \\
\hline 8 & Around & 731 & 0.15 & 3.17 \\
\hline 9 & Relatively & 612 & 0.13 & 2.66 \\
\hline 10 & Quite & 606 & 0.13 & 2.63 \\
\hline$\ldots$ & $\ldots$ & $\ldots$ & $\ldots$ & $\ldots$ \\
\hline & Total & 2301 & 4.87 & 100 \\
\hline
\end{tabular}

Our findings reveal that adverbs are the second most prominent grammatical category across the corpus of EFL education research articles after modal auxiliary verbs. The following are examples of adverbs acting as hedging devices in the EFL education research articles:

(12) About $38 \%$ of experienced teachers and $22 \%$ of prospective teachers expressed constructivist metaphors.

(13) So school teachers often complain of working burdens, and do not have enough time to converse with students in English.

(14) As the latter two groups outperformed the first group, the authors concluded that structured input rather than rule explanation was responsible for the superior learning results.

(15) Consequently, any context-specificity of beliefs established in this study is far more likely to be due to peculiarities of the academic specialization than to cultural differences.

\section{Adjectives acting as hedges}

The meaning of epistemic adjectives, according to Varttala (2001), is similar to that of the adverbs in the sense that they characterize the information presented as uncertain, tentative, or not quite precise. The findings of the present study revealed that in the corpus the overall number of epistemic adjectives $(n=7025)$ is less than the number of adverbs $(n=23.031)$. Table 10 demonstrates the comparative percentage of adjectives acting as hedges identified in the corpus of the present study.

Table 8. Frequencies of adjectives potentially used as hedges in the corpus

\begin{tabular}{llccc}
\hline $\mathbf{N}$ & Adjectives & F1 & F2 & $\%$ \\
\hline 1 & Most & 4629 & 0.97 & 65.9 \\
\hline 2 & Possible & 1766 & 0.37 & 25.1 \\
\hline 3 & consistent & 369 & 0.08 & 5.25 \\
\hline 4 & Seldom & 74 & 0.02 & 1.05 \\
\hline 5 & Plausible & 62 & 0.01 & 0.88 \\
\hline 6 & Rare & 62 & 0.01 & 0.88 \\
\hline 7 & Questionable & 32 & - & 0.45 \\
\hline 8 & Probable & 31 & - & 0.44 \\
\hline & Total & 7025 & 1.46 & 100 \\
\hline
\end{tabular}

As can be seen, the three most frequent adjectives across the compiled corpus are most $(65.9 \%)$, possible $(25.1 \%)$ and consistent with $(5.25 \%)$. This can be explained by genre specificity: researchers tend to generalize their findings (most), try to find possible explanation so as to fit in the general discourse, and to be consistent with other researchers appears to be one of the main features of scientific discourse. The following are examples of adjectives acting as hedging devices in the EFL education research articles:

(16) Like most previous researches, the study investigated the students' perception of technological resources.

(17) Also, in this turn the student is using the opportunity provided her to think through possible answers.

(18) This is consistent with arguments that support the role of motivation in learning languages.

(19) Even though learner errors can be taken as evidence of mental functioning, they are seldom welcomed as evidence of achievements, and seldom capitalized on for knowledge building.

(20) It thus seemed plausible that identifying the strategies used by successful language learners would make it possible to establish an ideal strategy agenda which could be used to train less successful learners.

\section{Nouns acting as hedges}

Epistemic nouns resemble many items discussed above in that they are all characterized by a component of tentative or indefinite meaning that 
makes them useful for hedging purposes. According to Varttala (2001), many of these nouns are derived from epistemic lexical verbs and adjectives; some of them have been already discussed above.

Table 9. Frequencies of nouns used as hedges in the corpus

\begin{tabular}{clccc}
\hline $\mathbf{N}$ & Nouns & F1 & F2 & $\%$ \\
\hline 1 & possibility & 381 & 0.08 & 25.4 \\
\hline 2 & assumption & 284 & 0.06 & 18.9 \\
\hline 3 & tendency & 239 & 0.05 & 15.9 \\
\hline 4 & probability & 148 & 0.03 & 9.8 \\
\hline 5 & prediction & 144 & 0.03 & 9.6 \\
\hline 6 & implication & 118 & 0.02 & 7.9 \\
\hline 7 & doubt & 115 & 0.02 & 7.7 \\
\hline 8 & (in)theory & 38 & - & 2.5 \\
\hline 9 & contention & 21 & - & 1.4 \\
\hline 10 & conjecture & 11 & - & 0.7 \\
\hline & Total & 1499 & 0.26 & 100 \\
\hline
\end{tabular}

The findings of the present study revealed that nouns, which were used as hedging devices, were the less frequent grammatical category, with a total of 1,499 . Among them, the most common nouns are possibility (25.4\%), assumption (18.9\%), and tendency (15.9\%). Table 9 demonstrates the comparative percentage of different adverbs acting as hedges identified in the corpus of the present study.

The following are examples of nouns acting as hedging devices in the EFL education research articles:

(21) One possibility is that error correction in both strictly L2 and content-based classrooms may be driven by the perceptual salience of errors.

(22) There is a commonly held assumption that frequency of writing leads to better writing.

(23) For vocabulary, a tendency in the same direction emerged, yet the effect was somewhat smaller and failed to reach statistical significance.

(24) It assigns a higher probability to fluent/grammatical sentences.

(25) This indicates that prediction of performanceapproach and performance-avoidance on attitude is exclusively based on self-concept.

RQ3: What are the functions of the identified hedging devices in the corpus of EFL academic research articles?

\section{Functions of hedges in the corpus}

According to the polypragmatic model of hedges developed by Hyland (1998a), hedging devices can be divided into accuracy-oriented, writer-oriented and reader-oriented hedges in terms of their functions.

1) Accuracy-oriented hedges help to present information as fully, accurately, and objectively as possible. Typical linguistic means to realize this hedging function include approximators of quantity, frequency, and degree.

2) Writer-oriented hedges are "writer-focused and aim to shield (protect) the writer from possible consequences of error by limiting personal commitment" (Hyland, 1998a, p. 170). This type of hedges is expressed by modal auxiliary verbs, epistemic adverbs, adjectives and nouns, epistemic lexical verbs, agentless passives, impersonal passives, attribution to the source. These are the most common examples.

3) The last functional category of hedges is readeroriented type. This type of hedges may be realized by using different pragmatic markers, such as asking questions, taking personal responsibility, addressing readers directly.

Figure 3 presents the frequency distribution of hedging devices according to their functions in the genre of EFL education research articles.

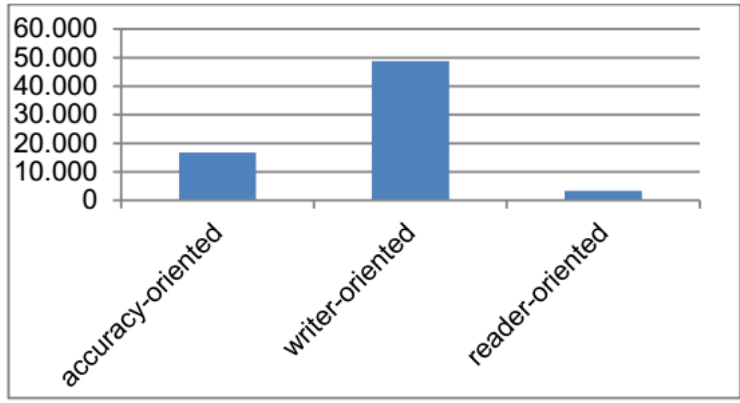

Figure 3. Overall distribution of hedging functions in the corpus

As can be seen, the writer-oriented function is the most prominent, accounting for $70.8 \%$ of hedges ( $n=48,777)$ in the corpus of EFL education research articles. Second is the accuracy-oriented function which compries $24.3 \% \quad(n=16,754)$. The least frequently used function is reader-oriented, which explains only $4.8 \%(n=3,320)$.

\section{Writer-oriented hedges}

The overall prominent position of writer-oriented hedges in the corpus of these EFL education research articles suggests that the researchers employ hedging devices primarily for the purpose of protecting themselves from the possible consequences of error by limiting their personal commitment.

As Hyland (1998a) argued, writer-oriented hedges function to reduce the risk of negatability in the sense that they "help to minimize writer's personal involvement and allow them to maintain a distance from the proposition, thus reducing the probability of refutation" ( $p$. 171). The main reason for authors to employ hedging devices in their writing appears to be the writer's desire to gain some distance from propositions due to wanting to adopt the conventional scientific writing style. Some of the typical examples of writer-oriented hedges are presented below:

(26) With regard to grammar teaching, the foreign course books are thought to be much better than the local English course books in terms of appropriate sequence of grammatical points, the increasing complexity of the structures to suit the suit the growing reading ability of the students, introducing the linguistic items in meaningful situations and including meaningful exercises on grammar points.

(27) The results of the survey largely appear to confirm this hypothesis.

(28) Evidently, certain goals such as travel orientation might be out the reach of students from disadvantaged backgrounds; whereas other 
goals such as wanting to make international friends might be more easily attained with the help of information technology and might be less influenced by socio-economic factors.

(29) However, such suggestions from materials writers are at times contradictory and are not always consistent with relevant research findings.

(30) These results suggest that existing lexical knowledge plays an important role in the wordlearning process and that children with learning problems may not use cues as efficiently as children with typical language development.

Accuracy-oriented hedges.

As for the accuracy-oriented hedges, Figure 3 above has demonstrated that this hedging function is the second most important category after the writeroriented hedging category in the corpus of EFL education research articles. Some of the typical examples are presented below:

(31) Perhaps a more disturbing and critical finding of the study was that about $33 \%$ of the students and $8 \%$ of the educators conceptualized the learner as the captive student (e.g., student as a slave, captive, prisoner, or trapped bird).

(32) At present, almost $80 \%$ however feel they understand most or all of what their teacher says in English.

(33) Further, although only a few students repeated a lesson as many as 12 times, the rate of repeating of lessons was approximately $14.8 \%$.

(34) Out of around 1100 features, only 20 features were selected.

As these examples show, a variety of devices indicating the degree or level of quantification or quality, such as about, almost, approximately, around, etc. are used to approximate or to hedge rather than to measure a factual quantity, frequency or degree. It can be seen that to present information as fully, accurately, and objectively as possible, the writers use a variety of degree of precision adverbs, which provide an acceptable degree if imprecision to specify the accuracy.

\section{Reader-oriented hedges}

Regarding the reader-oriented category of hedging functions, this type of hedges was found to be realized only in opinion articles. Particularly, at least $4.8 \%$ of all identified hedging devices in the corpus performed the function of reader-oriented hedges. The following examples can illustrate this hedging function:

(35) Generally speaking, the model is able to match the human word-order invertibility and animacy order behavior for both English and Japanese.

(36) I argue for the integration of the lexical approach with data-driven corpus-based methodology in English teaching, including ESP teaching, as I believe that the use of language corpora in the classroom can improve students' knowledge of the language and their ability to use it effectively.
The implicit pragmatic markers, such as parenthetical constructions, which reflect authors' personal opinions and stance (I argue, I believe) were used by the authors in order to mitigate the propositions in such a way that they seem to express deference, a sense of cooperation, and sharing and intimacy between the writer and the reader. In other words, reader-oriented hedges function as devices to establish good relationships and facilitate effective communication between the reader and the writer.

\section{CONCLUSION}

\section{Summary of the Study}

The present research was concerned with the study of the hedging phenomenon in EFL education research articles regarding the research questions:

RQ1: What are the major forms of hedging devices in EFL articles?

The findings of the present study confirm previous research (Hyland, 2000; Varttalla, 2011). The distribution of hedges in terms of categories shows that the major forms of hedges in the corpus are modal auxiliary verbs (44.9\%), followed by adverbs (33.45\%), adjectives $(10.2 \%)$, main verbs $(9.26 \%)$ and the nouns $(2.17 \%)$.

$R Q$ 2: What are the frequencies of the hedging devices?

The frequency of hedging devices in these EFL articles is 14.35 words per one thousand words in the compiled corpus. That is, $1.44 \%$ of words in the whole corpus are hedges. This finding indicates that the total amount of such devices is still relatively low in EFL articles.

RQ3: What are the functions of the identified hedging devices?

The qualitative results demonstrate that among the three pragmatic functions of hedges, the writer-oriented function was the most important in the corpus of EFL articles, accounting for $70.8 \%$ of the total number of hedges in the corpus.

These findings suggest that the main reason for employing hedging devices in the genre of $E F L$ articles is the researchers' desire to protect themselves from possible consequences of error by limiting their personal commitment to the propositions. The second reason is the researchers' desire to present the results of their studies as accurately and objectively as possible. The use of hedges involves a complicated process of thinking and selecting. As Hyland (1998b) noted, underlying scientific practice is the social tradition which guides researchers to behave in conformity to its norms and values, yet such norms and values are usually not clearly prescribed.

\section{Implications and limitations}

The findings of the present study may provide both theoretical and practical implications. Theoretically, this study fills the gap in the literature related to the hedging phenomenon in the genre of EFL education research articles, which has not been investigated in the previous research. In addition, the study demonstrates the applicability of the combined model of hedges to the investigation of the hedging 
phenomenon in this particular genre, consequently serving as an additional source of empirical studies on hedging in other genres apart from academic written/spoken discourse.

The present study encountered a number of limitations. The first issue concerns the notion of "hedging" itself. There is no unified definition of this phenomenon. Moreover, developing a complete and exhaustive taxonomy of hedging devices cannot be accomplished, since hedging is a contextual phenomenon and implies a variety of forms. The second limitation is the reliability of the researcher's non-native interpretation and identification of hedging devices, although the relevant literature was thoroughly reviewed by the researchers to validate subjective nonnative speaker analysis. Finally, the present study examined only language and linguistic genres. Future studies can be carried out using two corpora as materials for comparison.

\section{Suggestions for future research and concluding remarks}

There are a few suggestions for further research. The results of the general investigation of hedging devices in EFL education research articles are consistent with the previous studies revealing that hedging is an important component of academic discourse.

First, it is suggested that researchers could compile two corpora, for example, for comparing the use of hedging devices across two principally different genres: technical research articles and those in the humanities. Second, researchers might narrow down the study of hedging devices in terms of research questions. For example, apart from the forms, frequencies and functions of hedges, other sides of this phenomenon can be examined such as typical clusters and collocations of hedges. Third, researchers can apply different theoretical models for examining hedging devices to see if the results are different from those of the current study.

The results of this study showed the noteworthy presence of hedging devices in the compiled corpus of EFL education research articles. The study has provided useful information concerning the presence of the hedging phenomenon in academic discourse to illustrate that there is still room for further research into variations within this genre. It is hoped that the present study may inspire other researchers to further explore such important issues.

\section{ACKNOWLEDGEMENT}

This paper was partially granted by the Ministry of Science and Technology (MOST 104-2410-H-011022-MY2). Earlier version of this paper was revised and reshuffled according to the master's thesis of the second author (2014): A corpus-based study of hedging in EFL academic research articles.

\section{REFERENCES}

Dahl, T. (2008). Contributing to the academic conversation: A study of new knowledge claims in economics and linguistics. Journal of Pragmatics, 40, 1184-1201.

Evison, J. (2010). What are the basics of analyzing a corpus? In A. O'Keefe \& M. McCarthy (Eds.), The Routledge handbook of corpus linguistics (pp. 122-135). London: Routledge.

Falahati, R. (2007). A contrastive study of hedging in English and Farsi academic discourse (Unpublished Master's Thesis). Tehran University, Tehran.

Fraser, B. (2010). Pragmatic competence: The case of hedging. In G. Kaltenböck, W. Mihatsch and S. Schneider (Eds.), New approaches to hedging (pp. 15-34). Bingley: Emerald.

Hyland, K. (1998a). Hedging in scientific research articles. Amsterdam: John Benjamins.

Hyland, K. (1998b). Boosting, hedging and the negotiation of academic knowledge. Text, 18, 349-382.

Hyland, K. (2000). Hedges, boosters and lexical invisibility. Language Awareness, 9, 179-197.

Hyland, K. (2001). Humble Servants of the Discipline? Selfmention in Research Articles. English for Specific Purposes, 20, 207-226.

Hyland, K. (2005). Stance and engagement: a model of interaction in academic discourse, Discourse Studies, 7(2), 173-92.

Kaltenböck, G., Mihatsch, W., and Schneider, S. (2010). New approaches to hedging. Studies in Pragmatics, 9. Emerald Group Publishing Limited, America/Japan/India/Malaysia/China.

Lewin, B. A. (2005). Hedging: an exploratory study of authors' and readers' identification of 'toning down' in scientific texts. English for Academic Purposes, 4, 163-178.

Silver, M. (2003). The stance of stance: a critical look at ways stance is expressed and modeled in academic discourse. Journal of English for Academic Purposes, 2, 359-374.

Varttala, T. A. (1998). Remarks on the communicative function of hedging in popular scientific and specialist research articles in medicine. English for Specific Purposes, 18, 177-200.

Varttala, T. A. (2001). Hedging in scientifically oriented discourse: Exploring variation according to discipline and intended audience (Unpublished PhD dissertation). University of Tarnpereen Yliopisto, Finland.

Vass, H. (2004). Socio-cognitive aspects of hedging in two legal discourse genres. IBÉRICA, 7, 125141.

Wishnoff, J., R. (2000). Hedging your bets: L2 learners' acquisition of pragmatic devices in academic writing and computer-mediated discourse. Second Language Studies, 19(1), 119-148. 